Check for updates

Cite this: RSC Adv., 2018, 8, 38574

\title{
Effect of hydrothermal carbonization on dewatering performance of dyeing sludge $\uparrow$
}

\author{
Zhenjia Xu, ț ${ }^{\mathrm{ab}}$ Jun Zhou,,$^{\mathrm{b}}$ Yongdi Liu, ${ }^{\mathrm{b}}$ Lifeng $\mathrm{Gu},{ }^{\mathrm{c}}$ Xujun $\mathrm{Wu}^{\mathrm{c}}$ \\ and Xueying Zhang $(\mathbb{D}$ *a
}

The effects of hydrothermal carbonization (hydrothermal carbonization temperature, hydrothermal carbonization time, $\mathrm{pH}$ ) on the dehydration performance of dyeing sludge were studied. The specific resistance, viscosity and floccular morphology of sludge before and after hydrothermal carbonization were analyzed. The physical and chemical properties of the liquid were also determined. The results showed that the dehydration performance of sludge was optimum, when the reaction temperature was $180{ }^{\circ} \mathrm{C}$, the reaction time $4 \mathrm{~h}$ and the $\mathrm{pH}$ was 5.0 . Here the specific resistance to filtration and viscosity were $93.69 \%$ and $96.78 \%$ lower, respectively, than the control group. When the sludge was hydrothermally carbonized, the sludge flocs were broken due to extreme conditions of high temperature and high pressure, which formed a porous mesh structure with better water permeability. The cohesion of the sludge colloidal structure was reduced, the capillary suction time was reduced by $88.89 \%$, and the sludge dewatering performance was improved. This study shows the feasibility of the use of hydrothermal carbonization in sludge reduction.

Received 22nd June 2018

Accepted 10th November 2018

DOI: $10.1039 / \mathrm{c} 8 \mathrm{ra0} 5350 \mathrm{~b}$

rsc.li/rsc-advances dyeing sludge require attention in view of environmental protection and economics. ${ }^{3}$

At present, common methods used to improve sludge dewatering performance include chemical flocculant conditioning, ${ }^{4}$ heat treatment, ${ }^{5}$ ultrasonic treatment, ${ }^{6}$ electrolysis, ${ }^{7}$ and Fenton oxidation. ${ }^{8,9}$ The sludge dewatering process widely used in domestic sewage treatment plants involves the addition of conditioning agents such as calcium oxide or polyacrylamide to the sludge and the conditioned sludge undergoes mechanical dehydration. In theory, the sludge can be dewatered mechanically to reduce the moisture content to $60 \%$. In practice, the moisture content of the treated sludge is $70-76 \%{ }^{10,11}$ Due to the addition of conditioning agents, the volume of the cake after dewatering can increase by $0.5-0.8$ times, which is not conducive to subsequent disposal. The use of flocculants increases environmental threats and health risks. Polyacrylamide, the most common chemical flocculant, has been shown to be harmful to the environment and presents a carcinogenic risk. ${ }^{12}$ Not only that, due to the use of aluminium salts, it may also lead to human health problems including Alzheimer's disease. ${ }^{13}$ During heat treatment of sludge, malodorous gases are easily generated, and the resulting sludge has a low calorific value. Ultrasonic treatment and electrolysis do not produce odorous gases when used to treat sludge, but they do require specialized equipment, high energy consumption, and high maintenance costs. However, some low-molecular compounds (such as acetic acid, propionic acid, methanol, ethanol, and acetaldehyde) are continuously accumulated in the liquid phase during the Fenton oxidation process and cannot be completely mineralized. As
${ }^{a}$ College of Environmental Sciences and Engineering, Nanjing Tech University, Nanjing 211816, China. E-mail: xueyingzhang@njtech.edu.cn; Tel: +86-25-58139929

${ }^{b}$ College of Biotechnology and Pharmaceutical Engineering, Nanjing Tech University, Nanjing 211816, China

${ }^{c}$ Zhejiang Heze Environmental Technology Co., Ltd., Changxing, China

$\dagger$ Electronic supplementary information (ESI) available. See DOI: 10.1039/c8ra05350b

\$ These authors contributed equally to the article. 
$\mathrm{H}_{2} \mathrm{O}_{2}$ in the Fenton oxidation process has strong oxidizing properties, strict requirements related to equipment materials, high energy consumption, and high cost limit the practical engineering application of the process.

In recent years, research on hydrothermal carbonization of harmless renewable resources or energy has reached high interest globally. ${ }^{\mathbf{1 4 1 5}}$ Hydrothermal carbonization is a thermochemical process used to produce materials with a heating value similar to brown coal. ${ }^{16}$ It is a complex reaction, performed in a closed system using wet, carbohydrate rich biomass as raw materials under conditions of temperature $\left(180-260{ }^{\circ} \mathrm{C}\right)$ and high autogenous pressure. ${ }^{17}$ At present, hydrothermal carbonization is predicted a large potential in the preparation of carbon materials or carbon composites with different properties. Some researchers use hydrothermal carbonization to hydrolyze viscous organic substances in sludge at a certain temperature and pressure. The colloidal structure of the sludge is destroyed, and intracellular macromolecular organics are released, so that sludge dewatering performance is enhanced and the sludge is further converted into a carbon-based material that can be used as a fuel or i.e. biochar. In addition, the hydrothermal carbonization method overcomes various deficiencies of the above-mentioned conventional sludge treatment processes. Hydrothermal carbonization requires a small site area, short reaction period, is a stable operation with high relative efficiency and low energy consumption, and is a very promising sludge dewatering process. However, the optimum parameters of this technology and its performance are currently unclear. Based on a literature review, the present study is the first to adopt hydrothermal carbonization technology to treat dyeing wastewater sludge. By optimizing the processing conditions, an efficient sludge dewatering process was developed.

\section{Materials and methods}

\subsection{Materials}

The tested sludge was taken from a sewage treatment plant in Zhejiang Province, China, which was generated from the $\mathrm{A}^{2} / \mathrm{O}$ process (anoxic/anaerobic/aerobic) and was pretreated by plate and frame filtration. The experimental sludge was prepared by mixing sludge with deionized water and stirring to form a slurry (i.e. the sludge slurrying step, the mass ratio of sludge to water is $2.4: 1$ ). After slurrying, the experimental sludge was stored at $4{ }^{\circ} \mathrm{C}$ prior to hydrothermal carbonization. The basic properties of the experimental sludge after slurrying are shown in Table 1.

\subsection{Sludge hydrothermal carbonization}

Due to the limitation of resources and time, the whole study was divided into two parts. The first part of the study aimed to explore the effects of reaction temperature on the dewaterability of sludge. The temperature range of HTC was defined from 180 to $260{ }^{\circ} \mathrm{C} .{ }^{18}$ Therefore, the sludge was hydrothermally carbonized under four different temperatures - 180, 200, 220, and $240{ }^{\circ} \mathrm{C}$ for $3 \mathrm{~h}$. Afterward, the temperature let to the best dewaterability was chosen to further explore the influence of time $(1,2,3,4,5$, and $6 \mathrm{~h})$ and $\mathrm{pH}(5,7$, and 9) on the dewaterability of sludge.

Hydrothermal carbonization was carried out in a $2 \mathrm{~L}$ hightemperature and high-pressure reactor. The tested sludge and deionized water (the mass ratio of sludge to water is $2.4: 1$ ) were mixed into a slurry using a glass rod and poured into a hightemperature and high-pressure reactor. The sludge was agitated at $160 \mathrm{rpm}$ for $15 \mathrm{~min}$, and nitrogen was purged for $5 \mathrm{~min}$ to remove the air. The reactor was heated to the target temperature with the heating rate of $10{ }^{\circ} \mathrm{C} \mathrm{min}^{-1}$, and the reaction time started when the target temperature was reached.

In addition, considering the strong acid and alkali conditions, although the dewatering performance of the sludge was greatly improved, it also had serious environmental consequences; thus, weak acid and weak alkaline conditions were selected: $\mathrm{pH}=5, \mathrm{pH}=7.0$ (sludge $\mathrm{pH}$ after slurry was approximately 7.05), and $\mathrm{pH}=9.0$ (the original $\mathrm{pH}$ value of the sludge was 7.0. When adjusting the $\mathrm{pH}$ value, deionized water was replaced with a dilute sulfuric acid solution at pH 5.0 or a dilute sodium hydroxide solution at $\mathrm{pH}$ 9.0, and mixed with sludge in the same ratio as deionized water. Due to the strong buffering property of the sludge, a concentrated sulfuric acid or sodium hydroxide solution of $50 \%$ was added to the mixed sludge to adjust the sludge to the target $\mathrm{pH}$. At this time, the experimental group showed an increase in volume compared with the control group, and an equal volume of deionized water was added to the control group to eliminate any experimental errors).

During the hydrothermal carbonization experiment, the corresponding pressure was monitored using a gas pressure gauge. After the reaction time passed, the reactor was allowed to cool to room temperature. When the experiment was complete, the reaction product was collected (the hydrochar suspension), labelled, and stored at $4{ }^{\circ} \mathrm{C}$. Two sets of parallel experiments were performed for each set of experiments. All experimental data were averaged.

\subsection{General analysis}

The chemical oxygen demand (COD), $\mathrm{NH}_{4}{ }^{+}-\mathrm{N}$, total solids (TS), and volatile solids (VS) contents of the feed effluent samples were analysed according to the American Public Health Association protocol. ${ }^{19}$ The $\mathrm{pH}$ variations were measured using a $\mathrm{pH}$ meter (UB, China). Sludge floc morphological changes were observed using an electron microscope (SEM, S-3400N II

Table 1 Basic properties of sludge after slurrying ${ }^{a}$

\begin{tabular}{|c|c|c|c|c|c|}
\hline $\mathrm{pH}$ & TS (\%) & VS (\%) & $\operatorname{SRF}\left(10^{10} \mathrm{~m} \mathrm{~kg}^{-1}\right)$ & $\mathrm{CST}(\mathrm{s})$ & Viscosity (mPa s) \\
\hline $7.05 \pm 0.01$ & $17.29 \pm 0.15$ & $49.15 \pm 1.08$ & $5.89 \pm 0.12$ & $274.3 \pm 3.2$ & $2950 \pm 50$ \\
\hline
\end{tabular}

${ }^{a}$ TS, total solid; VS, volatile solid; SRF, specific resistance to filtration; CST, capillary suction time. 
Hitachi, Japan), and a Laser Particle Size Analyzer (Mastersizer 3000E, UK).

\subsection{Sludge settling velocity}

The sludge settling velocity (SV) is an indicator of the sedimentation performance of the sludge. Sludge samples were evenly mixed, and $100 \mathrm{~mL}$ of sludge was placed in a $100 \mathrm{~mL}$ graduated cylinder. After $0.5,1,2,4,8,12$, and $24 \mathrm{~h}$, respectively, the sludge volume below the sludge interface was determined.

\subsection{Capillary suction time}

Capillary suction time (CST) is the time required for a certain volume of filtrate obtained from the sludge to be absorbed by blotting paper via capillary force. ${ }^{20} \mathrm{CST}$ has been widely used to assess the effects of conditioning on sludge filterability and to determine the optimal dose of conditioners for dewatering processes. ${ }^{21}$

The standard CST instrument consists of two plastic blocks, a stainless-steel cylindrical funnel, a Whatman no. 17 filter paper (which is a standard grade of chromatography paper), and three electrodes fixed in the upper block and connected to an electrical timer. The test is carried out by pouring a small amount of sludge into the cylindrical tube. Then under the effect of capillary pressure, the sludge filtrate flows radially through the filter paper until it reaches the first two sensors that activate the timer. The timer stops when the flow reaches the third sensor, giving the CST value in seconds. The capillary suction pressure is much greater than the hydrostatic pressure inside the funnel and thus the test does not depend on the amount of sludge, but there must be a sufficient quantity to perform the test. ${ }^{22}$

It can be seen that the CST is also a function of various parameters such as filter paper properties, instrument properties and sludge-related properties in the following form:

$$
\mathrm{CST}=\varnothing\left[\frac{\mu C}{\chi}\right]
$$

where $\varnothing=$ a dimensionless instrument constant, $C=$ solid concentration, $\chi=$ filterability constant.

\subsection{Sludge viscosity}

Sludge viscosity was determined using the HAKKE VT550 rotary viscometer (Germany). The coaxial cylindrical measuring rotor system was selected with a shear rate range of $0-100 \mathrm{~s}^{-1}$, and the temperature was set to room temperature $\left(25^{\circ} \mathrm{C}\right)$. Prior to viscosity measurements, the sludge was stirred with an electric mixer, and then $100 \mathrm{~mL}$ of sludge was placed in a beaker. The average of multiple measurements was obtained to eliminate the impact of bubbles between the rotor and the cylinder.

\subsection{Specific resistance to filtration}

Specific resistance to filtration (SRF) has been used mainly as a measurement of dewaterability and to optimize sludge conditioning. The test is conducted by pouring a reasonable volume of sludge into the funnel (containing filter paper) and applying a vacuum (measured with a vacuum gauge) at time zero. During filtration, the filtrate volume is recorded as a function of time. These data are then plotted with inverse flux (time/filtrate volume) versus filtrate volume and the slope of the line is used to calculate the specific resistance. Most investigators determine SRF using the following equation: ${ }^{23}$

$$
\mathrm{SRF}=\frac{2 \Delta P A^{2} b}{\mu \omega}
$$

where $\Delta P=$ pressure difference (for the filtration process, pressure difference refers to liquid pressure), $A=$ filtration area, $b=$ slope of the line, $\mu=$ viscosity, $\omega=$ weight of dry cake solids per unit volume of filtrate.

\section{Results and discussion}

\subsection{Design of experiments (DOE)}

The design of this study could not comprehensively investigate the influence of temperatures on the dehydration performance of sludge under different residence time. However, Funke and Ziegler $(2010)^{24}$ revealed that the reaction rate of HTC was mostly dominated by the reaction temperature. Also, Suwelack et al. $(2016)^{25}$ revealed that the temperature was the main influential factor on HTC solid yield and carbonization, followed by citric acid (adjusting pH) and residence time. Therefore, the first part of the study only focused on how the temperature affects the dehydration performance of sludge. Moreover, the relatively long residence time $(3 \mathrm{~h}$ ) was primarily set to ensure a higher degree of carbonization. Afterward, the process condition was optimized based on the temperature which resulted in the best dehydration performance in the first part.

\subsection{Effect of different reaction temperatures on the dehydration performance of sludge after hydrothermal carbonization}

The results are shown in Fig. 1. Fig. 1(A) shows the characteristics of sludge settling performance. It can be seen from the figure that the sludge settling rate and the final settling performance are superior and inferior, respectively. The higher the proportion of supernatant after 24 hours sedimentation, the better the sludge sedimentation performance, the lower the hydrophilicity of the sludge, and the better the mud-water separation of the sludge. The amount of supernatant after $24 \mathrm{~h}$ sedimentation was $23.2 \%$, $20.1 \%, 21.5 \%$, and $19.5 \%$, respectively. The settling performance was best when the reaction temperature was $180{ }^{\circ} \mathrm{C}$ Fig. 1(A). Compared with the original sludge, which did not settle at all after $24 \mathrm{~h}$, and sedimentation of the sludge was largely improved. However, when the reaction temperature was increased, sedimentation of the sludge did not improve. The reason is that above $180{ }^{\circ} \mathrm{C}$, the hydrothermal carbonization reaction completely destroyed the cellular structure of the microorganisms in the sludge, and the viscous organic matter released after cell crushing formed carbon microspheres. This carbon microspheres have a completely different particle size distribution. The average sludge particles size in the system was smaller after 

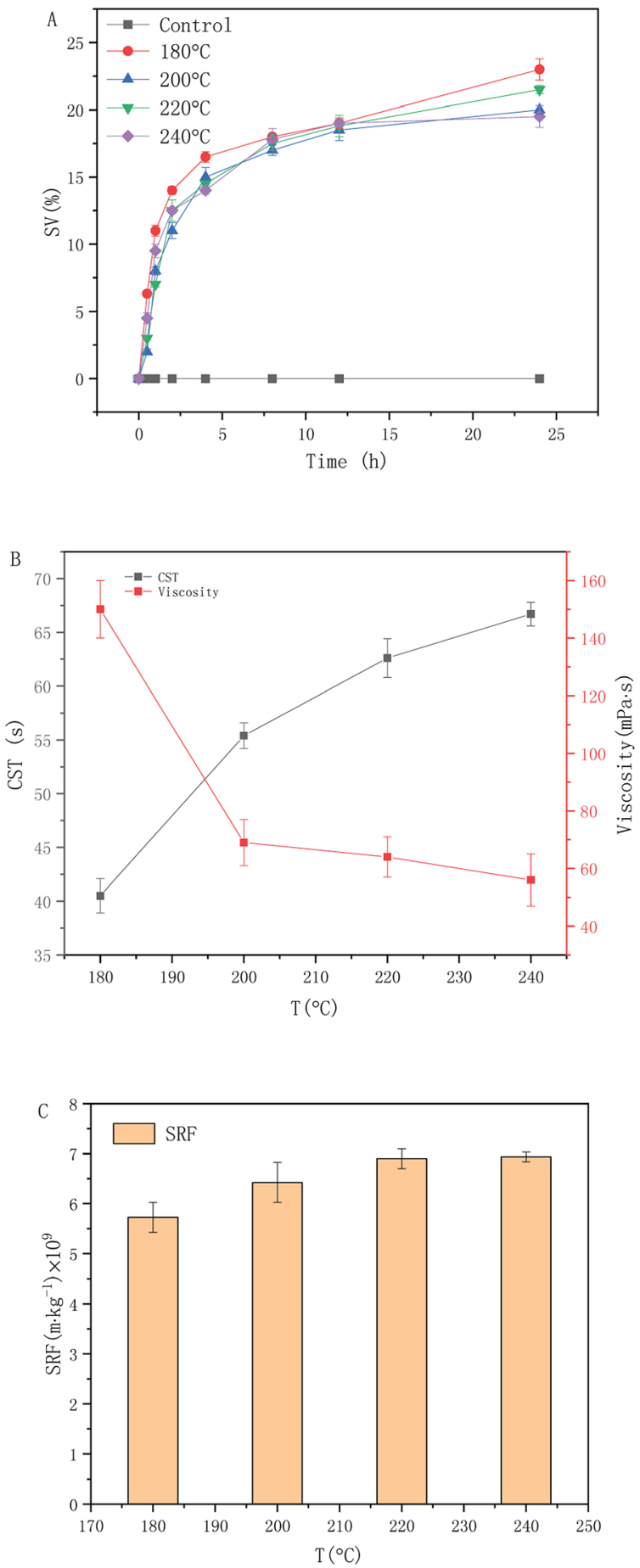

Fig. 1 Change of sludge properties after hydrothermal carbonization at different temperatures reaction conditions: settling performance changes (A), CST and viscosity changes (B) as well as SRF changes (C).

carbonization. ${ }^{26}$ As a result, the water holding capacity of the sludge was enhanced, resulting in a deterioration of sludge settling performance. In addition, a high proportion of super colloidal particles can also significantly increase the particle surface area/volume ratio, ${ }^{27}$ which not only enhances the degree of hydration of the sludge particles, impairs their dehydration performance, but also causes a significant increase in the dosage of dehydration conditioner.
The CST of the hydrochar suspension showed the opposite trend compare to viscosity Fig. 1(B). The CST of the hydrochar suspension treated at the four different temperatures was 40.5, $55.4,62.6$, and $66.7 \mathrm{~s}$, respectively. The CST was shortest at $180^{\circ} \mathrm{C}$ reaction time. Compared with the original sludge, the hydrochar suspension CST decreased by $85.24 \%$. However, the hydrochar suspension CST increased with increasing reaction temperature, indicating that the water holding capacity of the suspension was enhanced. From the viscosity curve of the suspension in Fig. 1(B), the viscosity of suspension after treated at the four different temperatures was 150,69 , and 64 , and $56 \mathrm{mPa}$ s, respectively, and the viscosity was lowest when the reaction temperature was $240{ }^{\circ} \mathrm{C}$. Compared with the original sludge, suspension viscosity decreased by $98.10 \%$. The viscosity of the suspension decreased with increasing temperature. During hydrothermal carbonization first the carbohydrates are hydrolyzed. This leads to a partial solubilization of the material. Than the sugars formed show an elimination of water to unsaturated compounds like furfurals. These furfurals polymerize to from micro sphere or other small particles. ${ }^{28}$ However, the carbon microspheres were too small to increase the water holding capacity of the suspension and caused a significant increase in the suspension CST. Under the $180{ }^{\circ} \mathrm{C}$ reaction conditions, the organic matter released from the sludge was hydrolyzed to small molecules. At this temperature, carbon microspheres were not formed in large numbers. Therefore, the main mode of sludge dehydration at present is mechanical dehydration. If the carbon microspheres are too small, they are likely to clog the filter, resulting in incomplete dewatering of the sludge. Therefore, $180{ }^{\circ} \mathrm{C}$ was the best choice. These findings are consistent with those shown in Fig. 1(A).

As shown in Fig. 1(C), the SRF of sludge treated at the four different temperatures was $5.73 \times 10^{9}, 6.42 \times 10^{9}, 6.89 \times 10^{9}$, and $6.93 \times 10^{9} \mathrm{~m} \mathrm{~kg}^{-1}$, respectively, and the SRF of sludge was lowest at $180{ }^{\circ} \mathrm{C}$ reaction temperature. Compared with the original sludge, suspension SRF decreased by $90.42 \%$. Excessively high temperatures also have an adverse effect on the suspension SRF. Higgins and Novak ${ }^{29}$ demonstrated that super colloidal particles with a particle size of 1-100 $\mu \mathrm{m}$ had the most significant effect on sludge dewatering. Carbon microspheres formed by the dehydration with consecutive condensation reaction of organic matter can easily block sludge filter cake or filter media, further affecting dewatering efficiency. In addition, a high proportion of super colloidal particles can also significantly increase the particle surface area/volume ratio, which not only enhances the degree of hydration of the sludge particles and impairs their dehydration performance, but also causes a significant increase in the dosage of dehydration conditioner. It can be concluded that a higher reaction temperature does not improve the dewatering performance of sludge Fig. 1(A and B). When the substantial cost and dehydration effect are considered, the reaction at $180{ }^{\circ} \mathrm{C}$ was optimal.

\subsection{Effect of different reaction times on the dehydration performance of sludge after hydrothermal carbonization}

Based on the results shown in Section 3.2, the excess sludge after pulping was selected and hydrothermal carbonization was 
carried out at $180{ }^{\circ} \mathrm{C}$ for $1,2,3,4,5$, and $6 \mathrm{~h}$. The effect of suspension dewatering performance is shown in Fig. 2. When the reaction time was 1-4 h, the sludge sedimentation performance gradually increased with reaction time. When the reaction time was $4 \mathrm{~h}$, the sludge sedimentation performance reached 29.2\% Fig. 2(A). As the reaction time was extended, the sludge settling performance began to decrease. When the flocs break down, it was found that the degree of hydration increases,
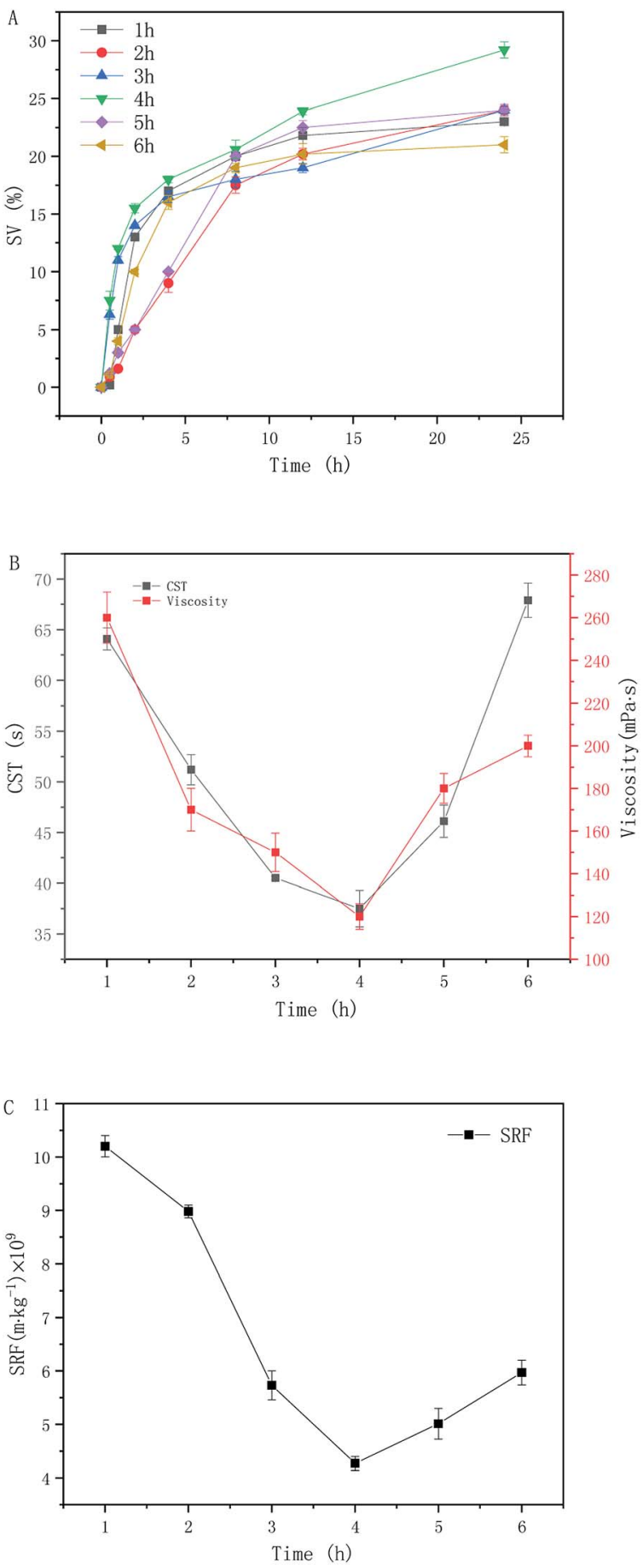

Fig. 2 Change of sludge properties after hydrothermal carbonization at different time reaction conditions: settling performance changes (A), CST and viscosity changes (B) as well as SRF changes (C). the water holding capacity of the sludge increases, and sedimentation of the sludge deteriorates. ${ }^{30,31}$

When the reaction time was 1-4 h, dewatering performance of the sludge increased gradually with prolongation of the reaction time; when the reaction time was 4-6 h, dewatering performance of the sludge decreased Fig. 2(B and C). Based on the original optimization shown in Section 3.2, when the reaction time was 4 hours, the suspension CST, viscosity, and SRF
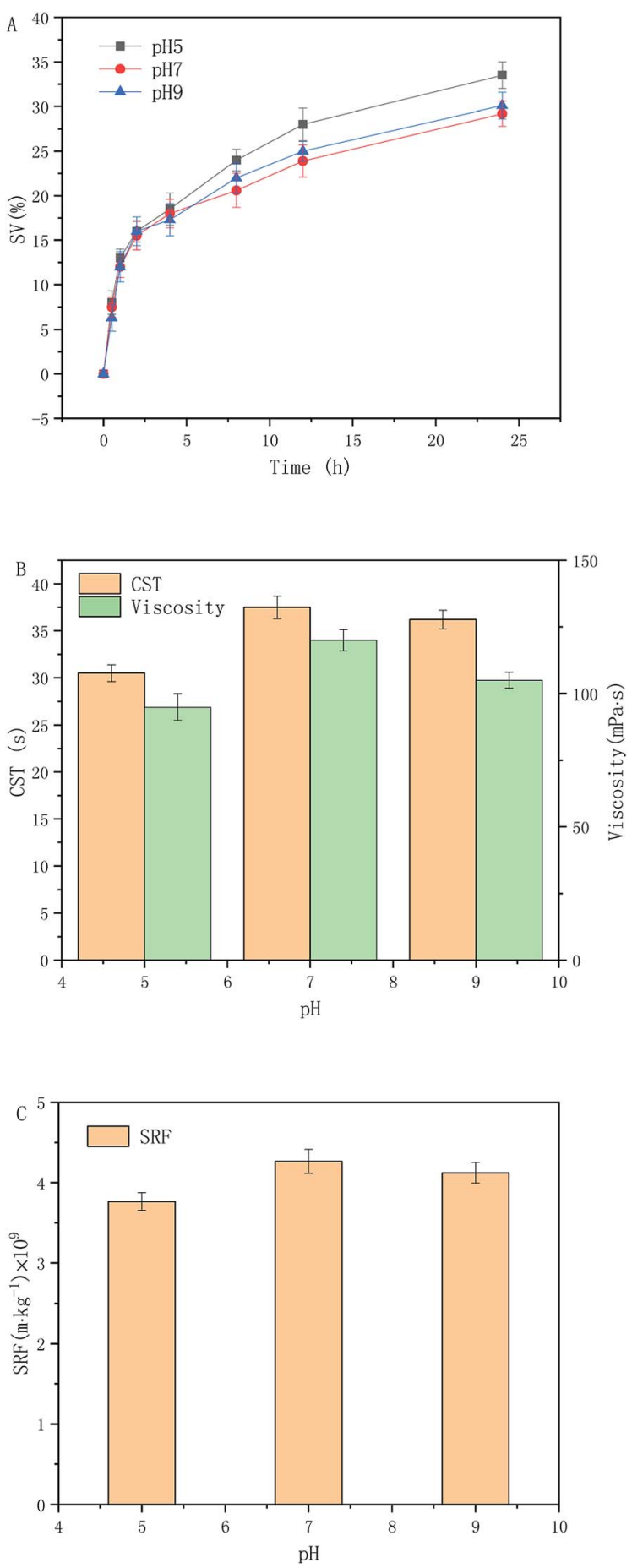

Fig. 3 Change of sludge properties after hydrothermal carbonization at different acid-base reaction conditions: settling performance changes (A), CST and viscosity changes (B) as well as SRF changes (C). 
were further reduced by $7.41 \%, 20.01 \%$, and $25.49 \%$, respectively. However, when the reaction time was longer than $4 \mathrm{~h}$, the hydrothermal carbonization treatment did not improve the dewatering performance of the sludge. This is due to the fact that the cell structure of sludge microorganisms (including cell walls and cell membranes) is further destroyed as the hydrothermal carbonization time (longer than $4 \mathrm{~h}$ ) increases. The intracellular organic compounds were released and converted into soluble substances. These organic substances included proteins, carbohydrates and lipids. As a result, the viscosity of the sludge increased, further deteriorating the dewatering performance of sludge occurs. Concluding, these findings indicate that the appropriate reaction time was $4 \mathrm{~h}$.

\subsection{Effect of different initial $\mathrm{pH}$ values on the dehydration performance of sludge after hydrothermal carbonization}

Based on the results shown in Section 3.2 and 3.3, the excess activated sludge at $\mathrm{pH}=5,7$, and 9 after slurrying was selected and hydrothermal carbonized at $180{ }^{\circ} \mathrm{C}$ for $4 \mathrm{~h}$. The results are shown in Fig. 3. From Fig. 3(A), it can be concluded that under acidic, neutral and alkaline conditions, after carbonization and $24 \mathrm{~h}$ sedimentation, the proportions of the supernatants were $33.5 \%, 29.2 \%$, and $30.1 \%$, respectively. When the $\mathrm{pH}$ was 5 , sedimentation of the sludge was best, which is consistent with the optimal $\mathrm{pH}$ (4.8) obtained by Wang. ${ }^{32}$ The zeta potential was close to the isoelectric point and the sludge flocculation settling performance was best at this $\mathrm{pH}$ value.

A correlation between the CST and viscosity change was observed Fig. 3(B). In relation to the CST changes, the initial pH values were $\mathrm{pH}=5,7$, and 9. After hydrothermal carbonization, the CST was 30.5, 37.5, and $36.2 \mathrm{~s}$, respectively. When the initial $\mathrm{pH}$ was 5 , the CST was shortest, and further decreased by $18.67 \%$ on the basis of the study shown in Section 3.3, which was $88.89 \%$ lower than that of the original sludge. In terms of changes in sludge viscosity, the viscosity of sludge after hydrothermal carbonization was reduced to $95 \mathrm{mPa}$ s when the initial pH was 5 . On the basis of the study shown in Section 3.3, a further reduction of $20.83 \%$ was noted, and the viscosity of the original sludge phase was reduced by $96.78 \%$. This was due to catalysis by $\mathrm{H}_{2} \mathrm{SO}_{4}$, accelerating the hydrolysis of a part of the less reactive organic materials (such as cellulose), which gradually began to hydrolyze into small molecules and further reduced the sludge viscosity. $\mathrm{Ye}^{33}$ demonstrated a positive correlation between sludge dewatering performance and viscosity, that is, dehydration performance deteriorated when viscosity increased. Therefore, hydrothermal carbonization at an initial $\mathrm{pH}$ of 5 is the best choice, which is consistent with the results shown in Fig. 3(A).

According to the results shown in Fig. 3(C), when the initial $\mathrm{pH}$ was 5 , the minimum specific resistance of the sludge was $3.77 \times 10^{9} \mathrm{~m} \mathrm{~kg}^{-1}$, which was $11.72 \%$ lower than the experimental results shown in Section 3.3. Compared with the original sludge, the reduction was $93.69 \%$. This is because $\mathrm{H}_{2} \mathrm{SO}_{4}$ is a strong electrolyte that acts as an electrification neutralizer and compresses the electric double layer, which can affect the zeta potential of the colloidal particles in the sludge, destroy the gel structure of the sludge, enhance the fluidity, and thus improve the dewatering performance of the sludge. In Fig. 3(A and B). It can be observed that $\mathrm{pH}=5$ was effective in enhancing sludge dewatering performance.

\subsection{Analysis of other physicochemical properties of sludge before and after hydrothermal carbonization}

From Table 2, it can be seen that the $\rho\left(\mathrm{NH}_{4}{ }^{+}-\mathrm{N}\right)$ and $\rho(\mathrm{COD})$ values in the sludge filtrate increased significantly during the hydrothermal carbonization process at $180{ }^{\circ} \mathrm{C}$ and reaction time of 1-4 $\mathrm{h}$, and these values increased with reaction time. The results showed that during the hydrothermal carbonization of sludge, microbial cells in the sludge were damaged, and the polymer which has a strong binding force with water molecules was hydrolyzed. In the initial stage of the reaction, the precursor was hydrolyzed into monomers, and the $\mathrm{pH}$ value of the reaction system was reduced, further promoting the release of water in the sludge flocs. The BOD/COD value was between 0.42 and 0.52 , which indicated that the sludge filtrate after hydrothermal carbonization showed good biodegradability. Sludge filtrate could be treated by fermentation to produce biomethane. ${ }^{34,35} \mathrm{In}$

Table 2 Physical and chemical properties of the sludge filtrate before and after hydrothermal carbonization

\begin{tabular}{|c|c|c|c|c|c|c|c|c|c|c|c|c|c|}
\hline & & \multirow{2}{*}{$\frac{\mathrm{pH}}{\text { After }}$} & \multicolumn{2}{|c|}{$\operatorname{COD}\left(\mathrm{mg} \mathrm{L}^{-1}\right)$} & \multicolumn{2}{|c|}{$\mathrm{BOD}\left(\mathrm{mg} \mathrm{L}^{-1}\right)$} & \multirow{2}{*}{$\frac{\text { BOD/COD }}{\text { After }}$} & \multicolumn{2}{|c|}{$\begin{array}{l}\mathrm{NH}_{4}{ }^{+}-\mathrm{N} \\
\left(\mathrm{mg} \mathrm{L}^{-1}\right)\end{array}$} & \multicolumn{2}{|l|}{ TS (\%) } & \multicolumn{2}{|l|}{ VS (\%) } \\
\hline & & & Before & After & Before & After & & Before & After & Before & After & Before & After \\
\hline \multirow[t]{3}{*}{$\mathrm{pH} 73 \mathrm{~h}$} & $180^{\circ} \mathrm{C}$ & 6.69 & 736 & 12505 & 313 & 5627 & 0.45 & 242 & 6555 & $17.29 \%$ & $14.11 \%$ & $49.15 \%$ & $52.97 \%$ \\
\hline & $200{ }^{\circ} \mathrm{C}$ & 6.93 & 703 & 11245 & 330 & 5285 & 0.47 & 259 & 7190 & $17.31 \%$ & $13.06 \%$ & $49.92 \%$ & $51.44 \%$ \\
\hline & $220^{\circ} \mathrm{C}$ & 6.55 & 720 & 5150 & 309 & 2678 & 0.52 & 235 & 5195 & $17.30 \%$ & $12.27 \%$ & $50.01 \%$ & $50.45 \%$ \\
\hline & $2 \mathrm{~h}$ & 6.73 & 718 & 22065 & 257 & 9267 & 0.42 & 234 & 5470 & $17.37 \%$ & $14.63 \%$ & $49.33 \%$ & $53.81 \%$ \\
\hline & $3 \mathrm{~h}$ & 6.69 & 708 & 12505 & 291 & 5627 & 0.45 & 252 & 6555 & $17.30 \%$ & $14.11 \%$ & $49.17 \%$ & $52.97 \%$ \\
\hline & $4 \mathrm{~h}$ & 6.44 & 737 & 16180 & 314 & 8252 & 0.51 & 260 & 5975 & $17.30 \%$ & $13.62 \%$ & $49.45 \%$ & $52.53 \%$ \\
\hline \multirow[b]{3}{*}{$180^{\circ} \mathrm{C} 4 \mathrm{~h}$} & $5 \mathrm{~h}$ & 6.36 & 708 & 17650 & 325 & 9178 & 0.52 & 230 & 5555 & $17.37 \%$ & $13.36 \%$ & $49.27 \%$ & $53.88 \%$ \\
\hline & $6 \mathrm{~h}$ & 6.06 & 732 & 19125 & 298 & 9945 & 0.52 & 242 & 5375 & $17.40 \%$ & $13.17 \%$ & $49.97 \%$ & $54.37 \%$ \\
\hline & pH 5 & 4.81 & 2945 & 25745 & 1228 & 14932 & 0.58 & 382 & 6114 & $16.96 \%$ & $13.32 \%$ & $49.95 \%$ & $51.23 \%$ \\
\hline
\end{tabular}




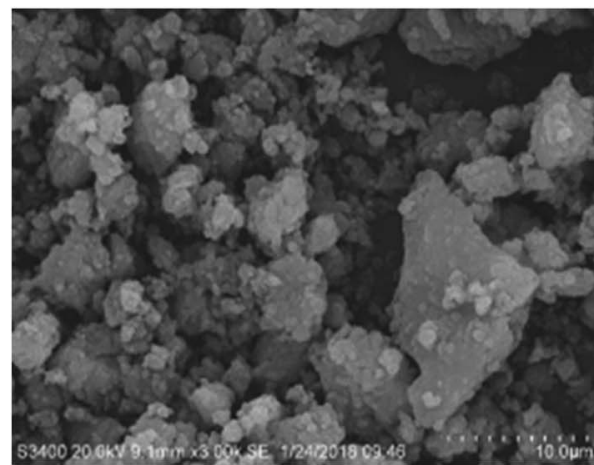

(A)

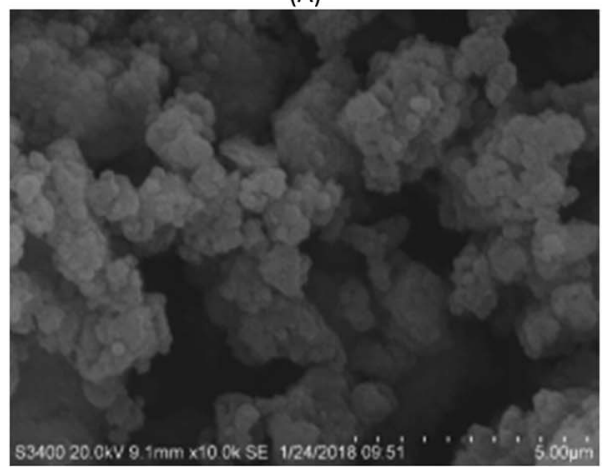

(B)

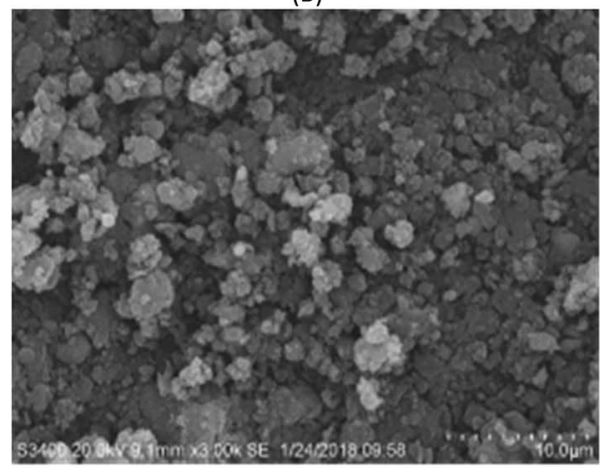

(C)

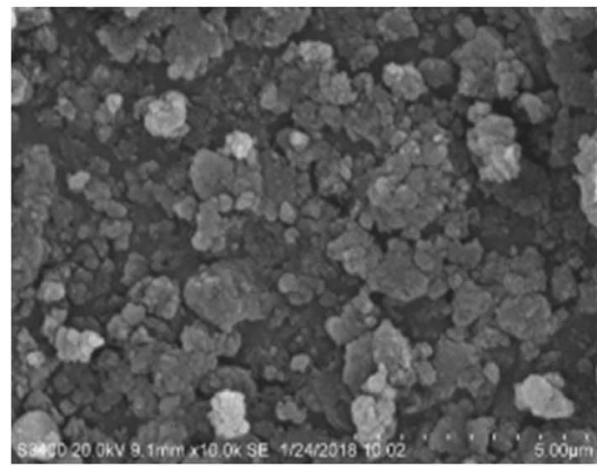

(D)

Fig. 4 SEM photograph of sludge before hydrothermal carbonization (A) and (B); SEM photograph of sludge after hydrothermal carbonization (C) and (D).

addition, proteins, carbohydrates, humic acids and other polymers that make the floccules negatively charged were hydrolyzed under hydrothermal conditions, which reduced the negative charge of the flocs and promoted the settlement of sludge flocs. Some water was released as free water, which enhanced the dewatering performance of the sludge. This is consistent with the experimental results shown in Section 3.2 and 3.3.

During the hydrothermal carbonization treatment of sludge at $200{ }^{\circ} \mathrm{C}$ to $240{ }^{\circ} \mathrm{C}$ and a reaction time of $4-6 \mathrm{~h}$, the levels of $\rho\left(\mathrm{NH}_{4}{ }^{+}-\mathrm{N}\right)$ and $\rho(\mathrm{COD})$ in the sludge filtrate gradually decreased with reaction temperature. This was due to the dehydration polymerization of organic matter (cellulose, protein) during hydrothermal carbonization to produce carbon microspheres $\left(0.4-6 \mu \mathrm{m}\right.$ in diameter).$^{36}$ The formation of carbon microspheres also indirectly leads to the deterioration of sludge dewatering performance, which is consistent with the results shown in 3.2. Excessive reaction time and excessive temperature did not improve the dewatering performance of sludge.

As shown in Fig. 4(A and B), the larger size, compact and dense distribution of the original sludge particles was more compact compared with Fig. 4(C and D), which shows the sludge after hydrothermal carbonization. The structure of the particles was loose, and formed a porous mesh structure with better water permeability. This also verified the aforementioned conclusions. Under the conditions of a reaction temperature of $180^{\circ} \mathrm{C}$, a reaction time of $4 \mathrm{~h}$, and a pH of 5.0, sludge flocs were broken down, the sludge particle size was reduced, and the degree of hydration was reduced, which in turn led to an increase in sludge dewatering performance.

\section{Conclusions}

(1) Based on the DOE of this study, the optimal condition for dewatering sludge was $\mathrm{pH}=5.0$ and residence time of $4 \mathrm{~h}$ at the reaction temperature of $180^{\circ} \mathrm{C}$; CST decreased from $274.3 \mathrm{~s}$ to $30.5 \mathrm{~s}$, a reduction of $88.89 \%$; sludge viscosity decreased from $2950 \mathrm{mPa}$ s to $95 \mathrm{mPa} \mathrm{s}$, a decrease of $96.78 \%$; SRF decreased from $5.98 \times 10^{10} \mathrm{~m} \mathrm{~kg}^{-1}$ to $3.77 \times 10^{9} \mathrm{~m} \mathrm{~kg}^{-1}$, a decrease of $93.69 \%$. Sludge dewatering performance was largely improved under these conditions. However, the process conditions (residence time and $\mathrm{pH}$ ) at other temperatures were not optimized.

(2) Hydrothermal carbonization time higher than $4 \mathrm{~h}$ and reaction temperature higher than $180{ }^{\circ} \mathrm{C}$ did not improve sludge dewatering performance. This was due to the fact that sludge broke down more thoroughly at this time and temperature, and although the viscosity of sludge started to decrease, the sludge particles were very fine and clogged the filter. Therefore, sludge dewatering performance deteriorated.

(3) The structure of sludge particles following this treatment process changed from dense to loose, and organic matter was released into the supernatant to form a porous mesh structure with better water permeability, thereby improving the compressibility and dehydration of the sludge.

\section{Conflicts of interest}

There are no conflicts to declare.

\section{Acknowledgements}

This work was supported by the National Key Research and Development Program of China (2016YFE0112800, 
2018ZX07208-009), the National Natural Science Foundation of China (21777069), and the Jiangsu Synergetic Innovation Center for Advanced Bio-Manufacture.

\section{References}

1 Y. Zhai, X. Liu, Y. Zhu, et al., Bioresour. Technol., 2016, 218, 183-188.

2 D. S. Daniel, M. L. Sui, G. A. Dykes, et al., Appl. Environ. Microbiol., 2015, 81, 6090-6097.

3 H. Yuan, N. Zhu and F. Song, Bioresour. Technol., 2011, 102, 2308.

4 J. P. Wang, S. J. Yuan, Y. Wang, et al., Water Res., 2013, 47, 2643-2648.

5 B. Guan, J. Yu, H. Fu, et al., Water Res., 2012, 46, 425-432.

6 G. Zhen, X. Lu, Y. Zhao, et al., Bioresour. Technol., 2012, 116, 259.

7 J. Xu, H. Yuan, J. Lin, et al., J. Taiwan Inst. Chem. Eng., 2014, 45, 2531-2536.

8 H. Liu, J. Yang, Y. Shi, et al., Chemosphere, 2012, 88, 235-239.

9 H. Liu, J. Yang, N. Zhu, et al., J. Hazard. Mater., 2013, 258259, 144-150.

10 M. N. Chong, B. Jin, C. W. Chow, et al., Water Res., 2010, 44, 2997-3027.

11 M. Citeau, O. Larue and E. Vorobiev, Water Res., 2011, 45, 2167-2180.

12 K. L. Dearfield, C. O. Abernathy, M. S. Ottley, et al., Mutat. Res., 1988, 195, 45-77.

13 S. C. Bondy, NeuroToxicology, 2010, 31, 575-581.

14 M. Tańczuk, W. Kostowski and M. Karaś, Energy Convers. Manage., 2016, 125, 121-132.

15 L. Zhang and Y. S. Liu, Environ. Sci. Pollut. Res., 2016, 23, 1-9.

16 Z. G. Liu and R. Balasubramanian, Appl. Energy, 2014, 114, 857-864.

17 H. ikberg, T. Ohraaho, F. Pileidis, et al., ACS Sustainable Chem. Eng., 2015, 3, 150927224922009.
18 M. Mäkelä, L. Fraikin, A. Léonard, et al., Water Res., 2015, 91, 11.

19 T. Tian, S. Qiao, X. Li, et al., Bioresour. Technol., 2017, 224, 41.

20 P. A. Vesilind, J. - Water Pollut. Control Fed., 1988, 60, 215220.

21 N. K. Shammas and L. K. Wang, Handbook of Environmental Engineering, 2008, vol. 7, pp. 273-342.

22 T. T. More, S. Yan, N. V. Hoang, et al., Bioresour. Technol., 2012, 121, 425-431.

23 G. H. Yu, P. J. He and L. M. Shao, Water Res., 2010, 44, 797.

24 A. Funke and F. Ziegler, Biofuels, Bioprod. Biorefin., 2010, 4(2), 160-177.

25 K. U. Suwelack, D. Wüst, P. Fleischmann, et al., Biomass Convers. Biorefin., 2016, 6(2), 151-160.

26 M. Sevilla and A. B. Fuertes, Chemistry, 2009, 15, 4195.

27 E. Lombi, E. Donner, E. Tavakkoli, et al., Environ. Sci. Technol., 2012, 46, 9089-9096.

28 M. Sevilla and A. B. Fuertes, Carbon, 2009, 47, 2281-2289.

29 M. J. Higgins and J. T. Novak, Water Environ. Res., 1997, 69, 215-224.

30 H. Ge, P. D. Jensen and D. J. Batstone, Water Res., 2011, 45, 1597.

31 G. Zhang, J. Yang, H. Liu, et al., Bioresour. Technol., 2009, 100, 1505-1509.

32 L. L. Wang, L. F. Wang, X. M. Ren, et al., Environ. Sci. Technol., 2012, 46, 737.

33 F. Ye, X. Liu and Y. Li, J. Hazard. Mater., 2012, 199-200, 158163.

34 A. Shanableh, Water Res., 2000, 34, 945-951.

35 A. Valo, H. Carrère and J. P. Delgenès, J. Chem. Technol. Biotechnol., 2010, 79, 1197-1203.

36 L. Bennamoun, P. Arlabosse and A. Léonard, Renewable Sustainable Energy Rev., 2013, 28, 29-43. 